\title{
Analysis and simulation of single phase-to-ground short circuit fault in Van 154 kV substation: An experimental assessment
}

\author{
Sabir Rustemlia*, Ilter Demirb \\ a Department of Electrical-Electronics Engineering, Faculty of Engineering and Architecture, Bitlis Eren University, Bitlis, 13100, Turkey \\ b TEİAȘ, Van, Turkey
}

\section{A R T I C L E INFO}

Article history:

Received 01 November 2019

Received in revised form 09 December 2019

Accepted 10 December 2019

Keywords:

Single Phase-to-Ground Fault

Short Circuit Currents

Fault Analysis

MATLAB

\begin{abstract}
A B S T R ACT
It is necessary to know the short circuit current values of transmission and distribution lines, network equipment, transformers, breakers, fuses etc. to select and install protection systems in an electrical network. It is vital to make this selection correctly for safety, continuous operation, keep supplied power quality in an appropriate level and protect customers from adverse effects of both short circuit currents and outbreaks. In this paper, single phase-to-ground fault short circuit currents which are possible to occur in Van $154 \mathrm{kV}$ substation are modelled under MATLAB / Simulink platform. Simulation results are compared with actual data which is taken from digital relays of substation. Comparison results prove the validation of simulation system.
\end{abstract}

\section{Introduction}

Consumers are more likely to be affected by faults in energy distribution systems than faults in production and transmission systems. Since the production and transmission systems are installed in a much disorganized manner, all of them or a significant portion of them are not disabled at the same time. There is always an alternative supply to the consumption zones. Short-circuit is insulation breakdown between phase conductors or in star point grounded networks insulation breakdown between phase conductors and ground in any way, or it is a fault reached a very large current value due to wrong operations in electrical installations. In shortcircuit large short-circuit currents passing through circuit cause dynamic forces form on equipment and force them mechanically. Long-term, continuous short-circuit currents cause equipment heat up. If equipment is selected and installed to withstand the effects of the short-circuit in the time determined by the relays, there is no problem. However, if this equipment does not have a sufficient capacity, they will destroy and damage the environment. Also, they will endanger the safety of life and property. As a result of faults caused by shortcircuit event, the operation stops partially or completely and gradually the power generation, transmission, distribution and consumption can no longer continue normally. For this reason, defective parts of the plant should be separated from the solid parts by means of various protection elements (fuse, disconnector, breaker, etc.) as soon as possible (Küçük, 2005).

Short-circuit currents are the important parameters for the design and installation of electrical equipment, the operation of power systems and the analysis of faults. The calculation of short-circuit currents provides information about the design of power systems. Electrical power systems should be planned, projected, constructed and operated in a way to ensure safe, reliable and economic supply of electric load. Short-circuit failures in power systems are inevitable, even if careful planning and design are carried out, even if the system is well maintained and functioning perfectly. A short-circuit can cause active and reactive power oscillations by stimulating the mechanical oscillations of the generator units. This may cause problems in the stability of power transfer (Schlabbach, 2005).

\footnotetext{
* Corresponding author.

E-mail address: srustemli@beu.edu.tr
} 
Simple and precise simulation of system components can be performed using digital computers. By this way, short circuit currents can be calculated accurately (Parise et al. 1995).

Transformers are one of the most important equipment of power systems. $70-80 \%$ of faults in transformers are caused by short-circuits between windings (Butler-Purry and Wang, 2003).

Circuit breakers are used as protection equipment in the shortcircuit and overload conditions. (Mützel et al. 2007).

In the short-circuit calculations, two currents, the highest short-circuit current and the lowest short-circuit current, are taken into account. The capacity and classes of electrical equipment in the system are determined according to the highest short-circuit current. When selecting and setting fuses and protection devices, the lowest short-circuit current is taken into account (Serrican, 2007).

In this paper, single phase-to-ground fault short-circuit currents which are possible to occur in Van (Turkey) $154 \mathrm{kV}$ substation are modelled under MATLAB / Simulink platform.

\section{Mathematical calculation of single phase-to- ground fault short circuit current}

Among the fault types, single phase-to ground short circuit fault occurs most often then three phase short circuit fault (Hung et.al. 2010). The single phase-to-ground fault is usually referred as "short circuit" fault and occurs when one conductor falls to ground. When a fault occurs on a distribution line, it is very important to identify the fault location as quickly as possible so as to restore power as soon as possible.

Also when a single phase-to-ground short circuit fault occurs on an overhead equilateral triangular designed radial distribution line, the power supply has to be switched off (Han et.al. 2007).

As this paper focused on it, the general representation of a single phase-to-ground fault is shown in figure $1 . \mathrm{Z}_{\mathrm{f}}$ is the ground fault point impedance. Figure 2 shows the sequences diagram of network.

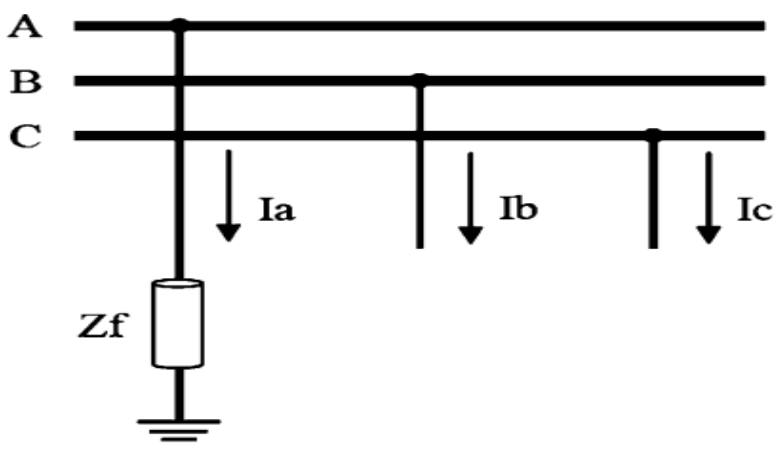

Figure 1. Single phase-to-ground fault (Huang et.al. 2010)

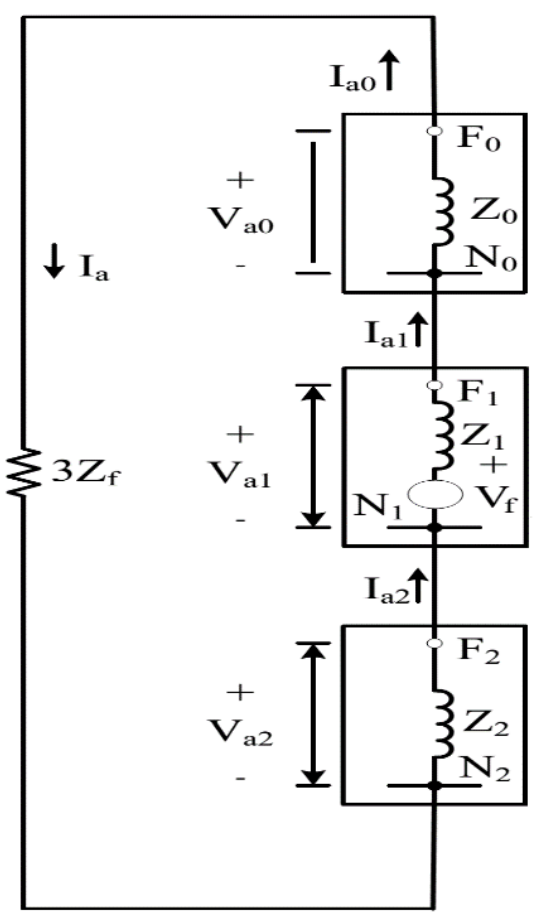

Figure 2. Positive, negative and zero components

As seen in figure 2, positive, negative and zero component currents are equal to each other. Therefore;

$I_{a 0}=I_{a 1}=I_{a 2}=\frac{V_{f} \angle 0^{\circ}}{Z_{0}+Z_{1}+Z_{2}+3 Z_{f}}$

Since;

$\left[\begin{array}{l}I_{a} \\ I_{b} \\ I_{c}\end{array}\right]=\left[\begin{array}{ccc}1 & 1 & 1 \\ 1 & a^{2} & a \\ 1 & a & a^{2}\end{array}\right]\left[\begin{array}{c}I_{a 0} \\ I_{a 1} \\ I_{a 2}\end{array}\right]$

If the equation is solved for the fault current of phase A;

$I_{a}=I_{a 0}+I_{a 1}+I_{a 2}$

$I_{a}=3 I_{a 0}=3 I_{a 1}=3 I_{a 2}$

From figure 1, it can be obtained;

$V_{a f}=Z_{f} I_{a}$

So;

$V_{a f}=Z_{f} 3 I_{a 1}$

Also;

$V_{a f}=V_{a 0}+V_{a 1}+V_{a 2}$

Therefore;

$3 Z_{f} I_{a 1}=V_{a 0}+V_{a 1}+V_{a 2}$ 
By using these equations, the following matrix is formed;

$\left[\begin{array}{c}V_{a 0} \\ V_{a 1} \\ V_{a 2}\end{array}\right]=\left[\begin{array}{c}0 \\ V_{f} \\ 0\end{array}\right]-\left[\begin{array}{ccc}Z_{0} & 0 & 0 \\ 0 & Z_{1} & 0 \\ 0 & 0 & Z_{2}\end{array}\right]\left[\begin{array}{c}I_{a 0} \\ I_{a 1} \\ I_{a 2}\end{array}\right]$

Then;

$V_{a 0}=-Z_{0} I_{a 0}$

$V_{a 1}=V_{f}-Z_{1} I_{a 1}$

$V_{a 2}=-Z_{2} I_{a 2}$

So, phase A voltage with reference to ground at the fault point can be found by the equation that given in (11);

$V_{a f}=V_{f}-\left[Z_{0}+Z_{1}+Z_{2}\right] I_{a 1}$

If the single phase-to-ground fault occurs on other phases, the voltages can be found by using symmetrical components relation as follows;
$\left[\begin{array}{c}V_{a f} \\ V_{b f} \\ V_{c f}\end{array}\right]=\left[\begin{array}{ccc}1 & 1 & 1 \\ 1 & a^{2} & a \\ 1 & a & a^{2}\end{array}\right]\left[\begin{array}{c}V_{a 0} \\ V_{a 1} \\ V_{a 2}\end{array}\right]$

So it can be obtained;

$$
\begin{aligned}
& V_{b f}=V_{a 0}+a^{2} V_{a 1}+a V_{a 2} \\
& V_{c f}=V_{a 0}+a V_{a 1}+a^{2} V_{a 2}
\end{aligned}
$$

\section{Simulation and fault analysis}

Single line diagram of Van $154 \mathrm{kV}$ Substation is given in figure 3. This diagram is taken as base for modelling the system under MATLAB / Simulink platform. Also the simulation model is given in figure 4.

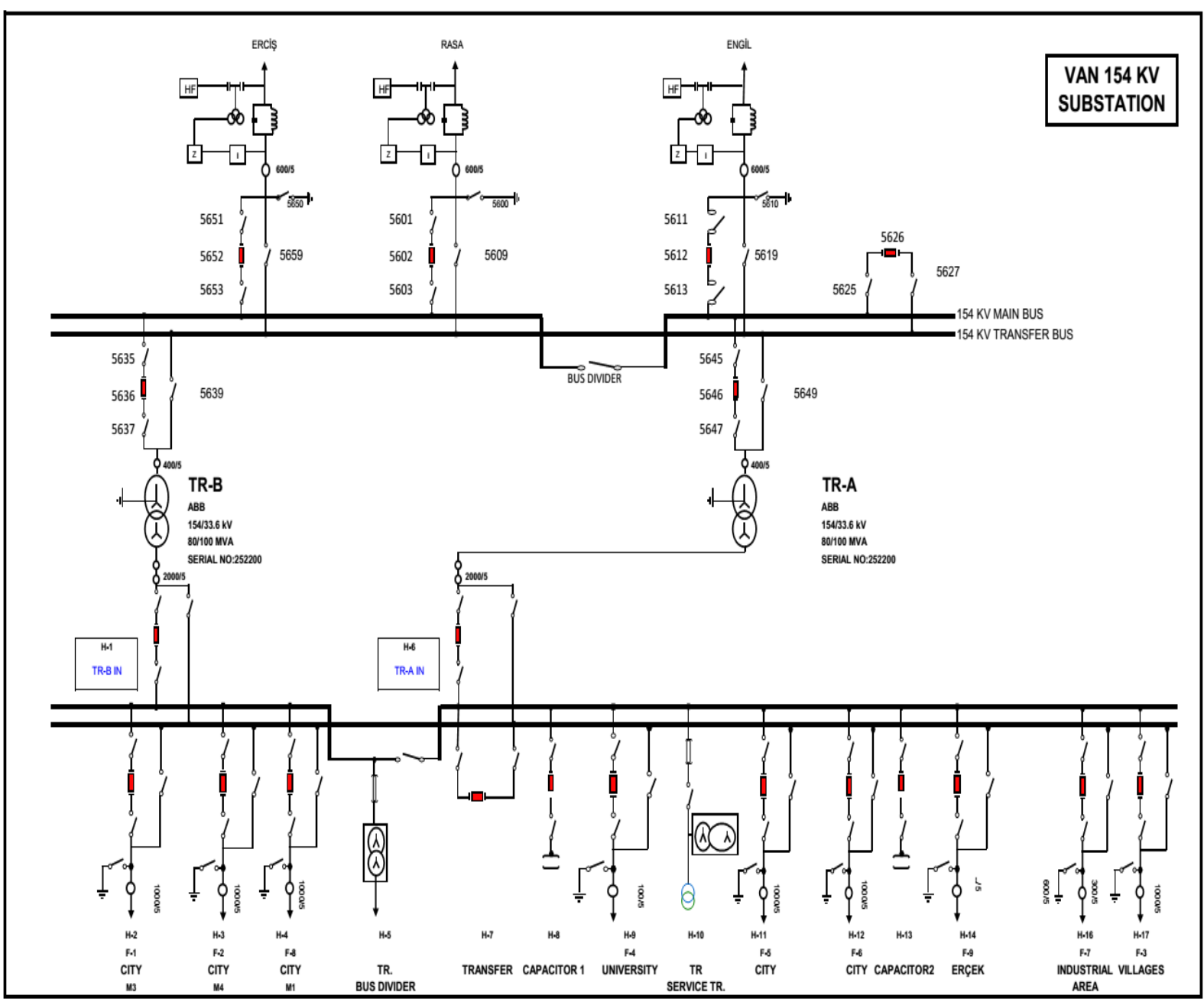

Figure 3. Single line diagram of Van $154 \mathrm{kV}$ Substation 


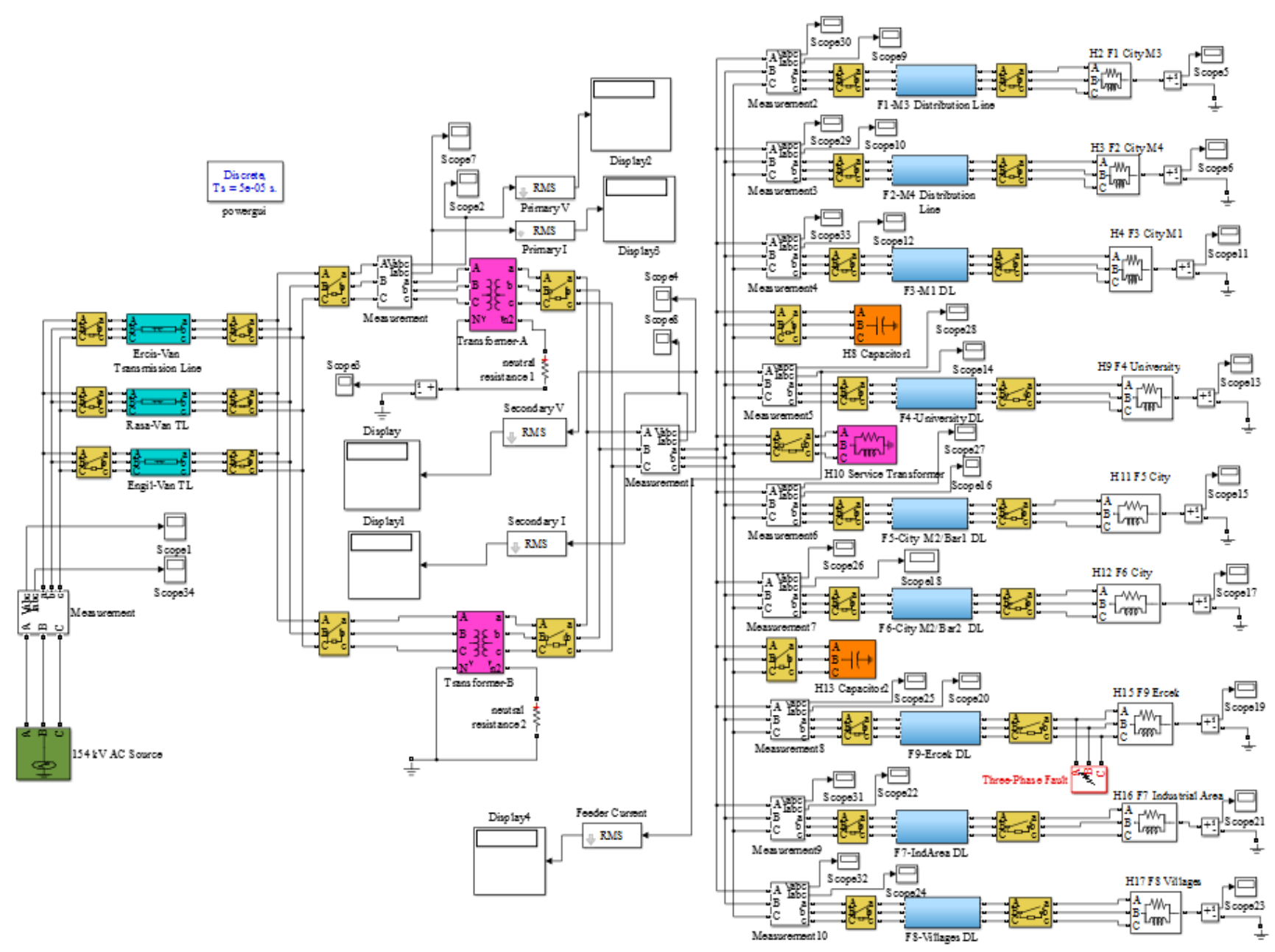

Figure 4. MATLAB Simulink model of the system

Table 1 describes the loading values of distribution lines. These are actual values and taken directly from $154 \mathrm{kV}$ Van Substation feeders. Also feeders are described by their actual names in system. When the single phase-to-ground short circuit occurs on a feeder at the $33.6 \mathrm{kV}$ medium voltage side of the system, short circuit relays record the current values. Single phase-to-ground fault occurs at C-Phase. Actual graph that taken from relay is shown in figure 5. This graph represents the short circuit currents of all phases and also the neutral current of system during single phase-to-ground short circuit fault which occurs at C-Phase.

Table 1. Van $154 \mathrm{kV}$ Substation loading values

\begin{tabular}{ccc}
\hline FEEDER & P (MW) & Q(MVAR) \\
\hline H-2F-2 CITY M3 & 17 & 1.7 \\
H-3 F-2 CITY M4 & 25 & 2.5 \\
H-4 F-3 CITY M1 & 20 & 2 \\
H-8 CAPACITOR 1 & 0 & 10 \\
H-9 F-4 UNIVERSITY & 2.2 & 0.22 \\
H-10 SERVICE TR & 0.1 & 0.04 \\
H-11 F-5 CITY M2 & 29 & 2.9 \\
H-12 F-6 CITY M2 & 15 & 1.5 \\
H-13 CAPACITOR 2 & 0 & 10 \\
H-15 F-9 ERÇEK & 12 & 1.2 \\
H-16 F-7 IND. AREA & 0.3 & 0.03 \\
H-17 F-8 VILLAGES & 6 & 0.6 \\
\hline
\end{tabular}

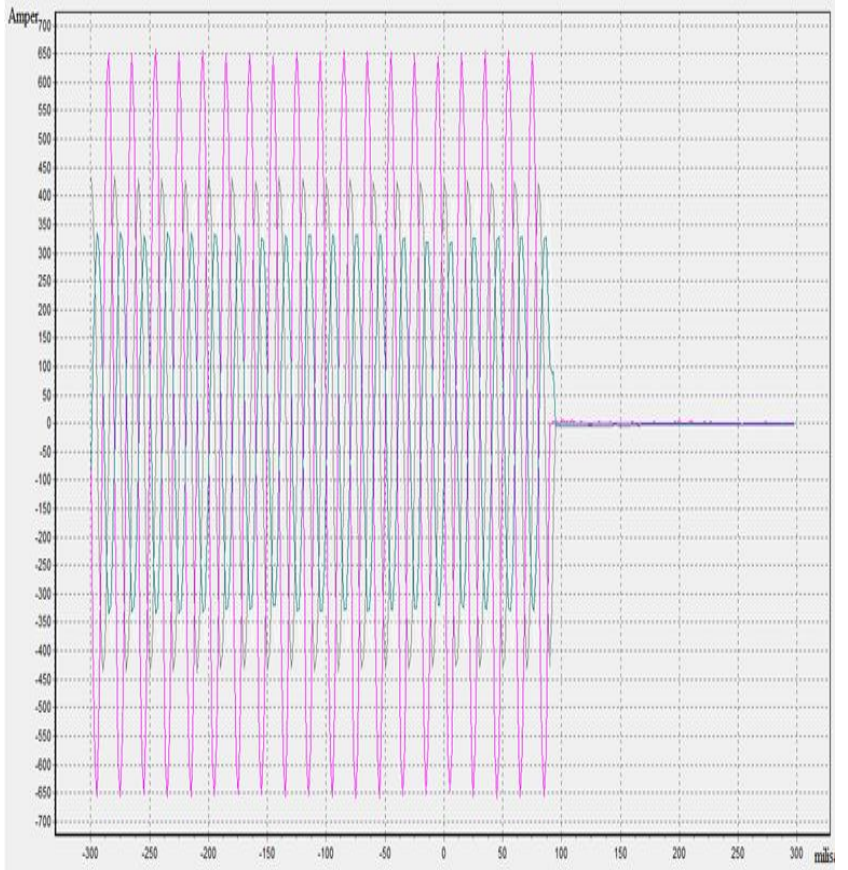

Figure 5. Relay current graph while C-Phase-to-ground fault occurs 


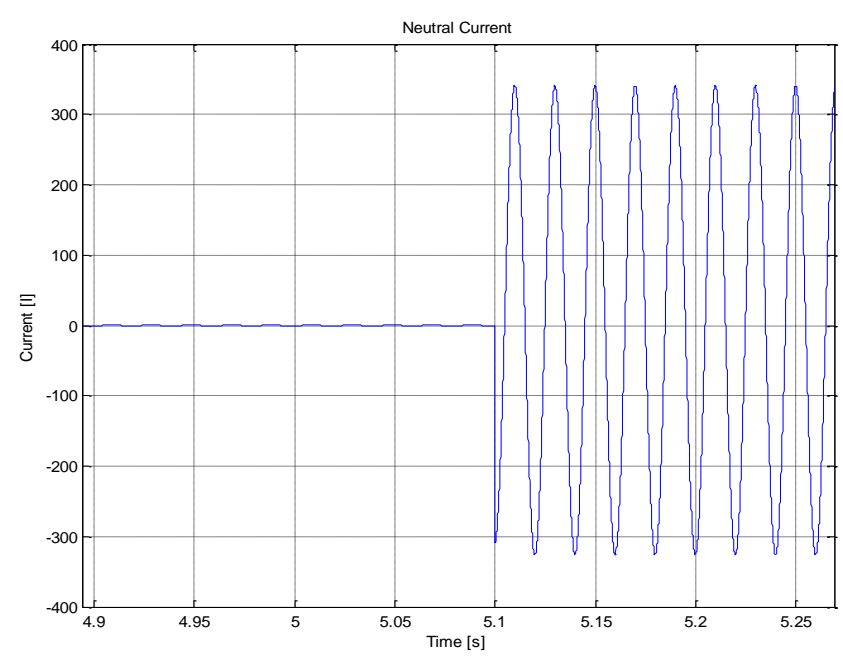

Figure 6. Neutral current graph of simulation system while C-Phaseto-ground fault occurs

\section{Results}

As it is seen from figure 5, I0 neutral current that represented by green line has a peak value of approximately 340 Amperes. Figure 6 shows the neutral current that taken from designed simulation system. Value of the neutral current while fault occurs is 341 Amperes. As the neutral currents that given in figure 5 and figure 6 are compared, it can be seen that actual system data is appropriate with simulation. So, designed simulation system represents the actual system and can be used for analysis.

Effects of single phase-to-ground short circuit fault at various points of the system are given comparative by normal operation conditions graphs as follows. Fault started at 5.1th second of simulation.

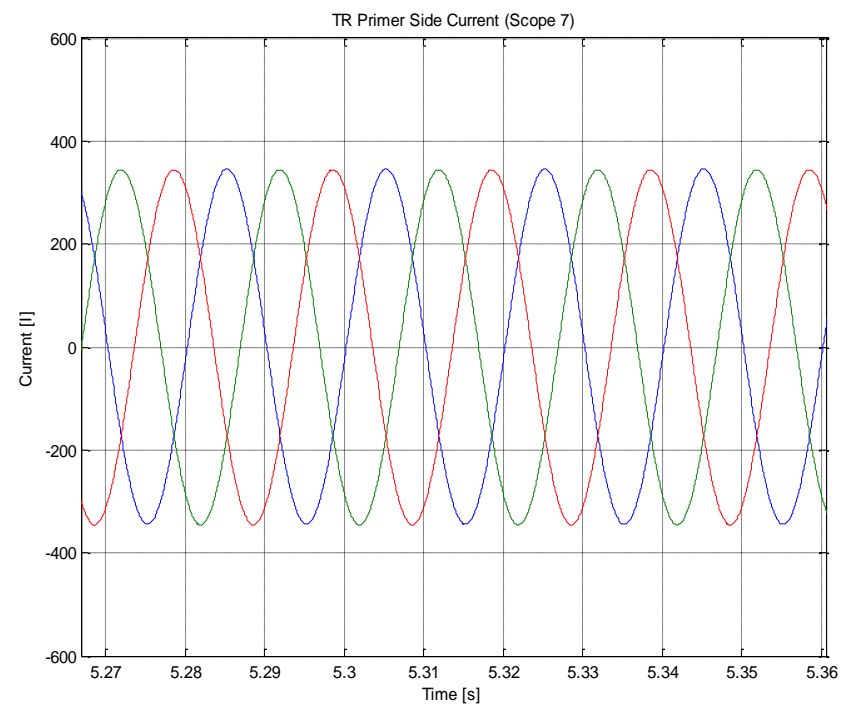

Figure 7-a. Primer side current graph of transformer at normal operation

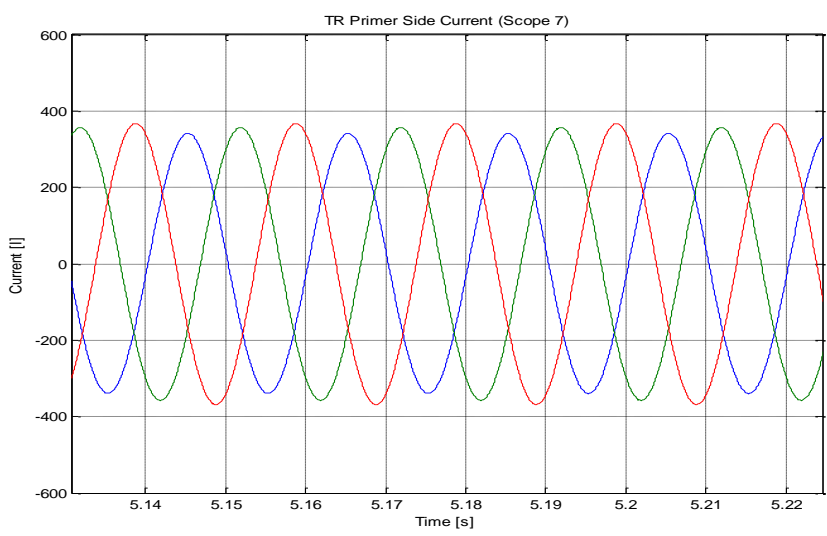

Figure 7-b. Primer side current graph of transformer during fault conditions

Figures 7-a and 7-b show the transformer current graphs of $154 \mathrm{kV}$ side at normal operation and during single phase-toground fault respectively. As it is seen from graphs, single phase-to-ground fault at secondary side of transformer has tolerable effect on primary side currents of transformer.

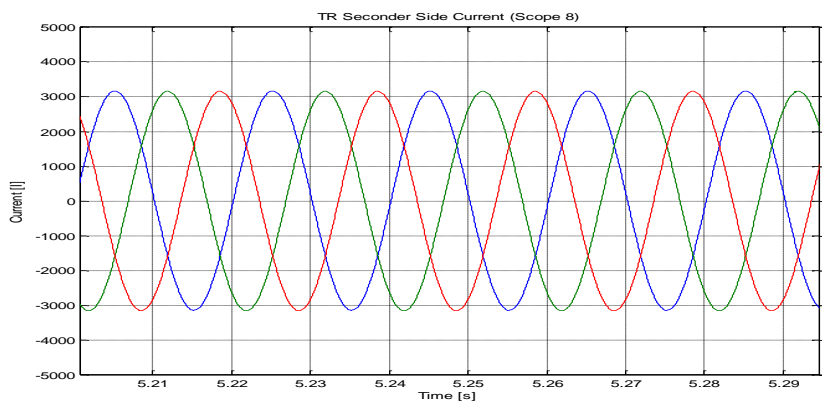

Figure 8-a. Seconder side current graph of transformer at normal operation

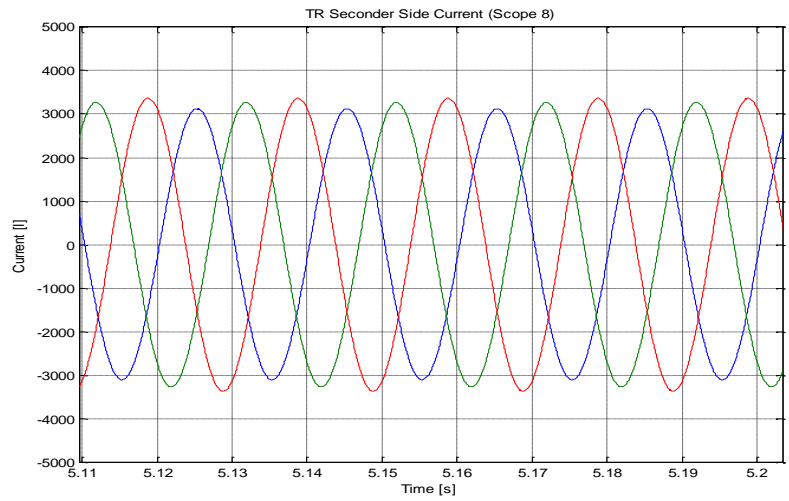

Figure 8-b. Seconder side current graph of transformer during fault conditions

Figures 8-a and 8-b show the transformer current graphs of $33.6 \mathrm{kV}$ side (secondary side) at normal operation and during single phase-to-ground fault respectively. Also single phase-toground fault at secondary side of transformer has tolerable effect on secondary side currents of transformer same as primary side. 


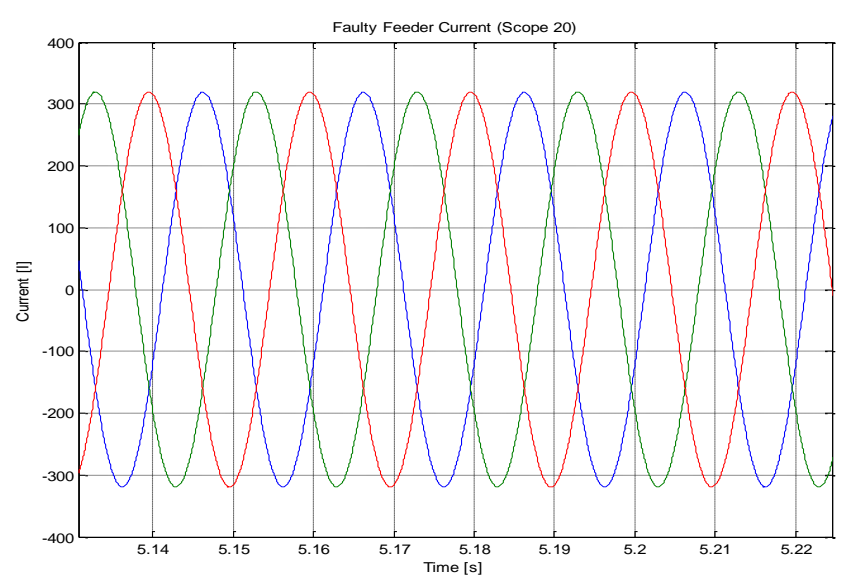

Figure 9-a. Current graph of faulty feeder at normal operation

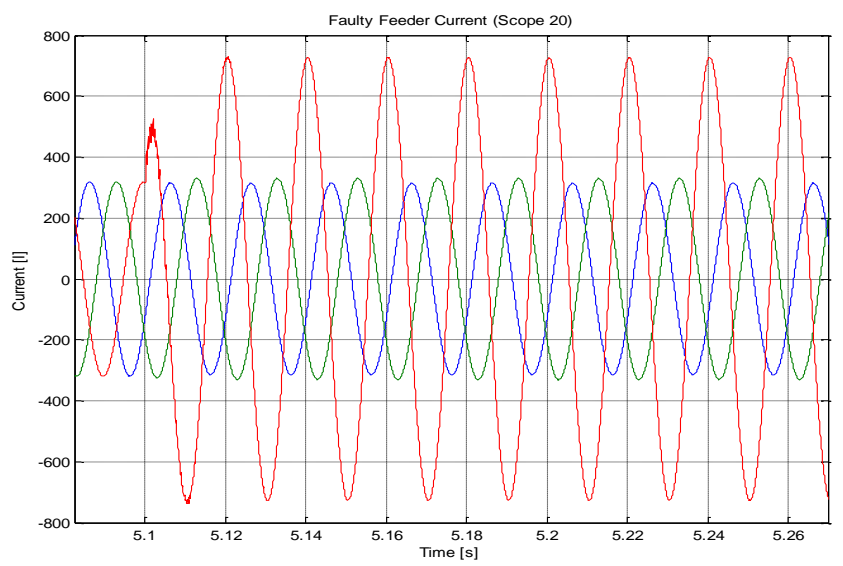

Figure 9-b. Current graph of faulty feeder during fault conditions

Figures 9-a and 9-b show the current graphs of the feeder that single phase-to-ground fault occurs at normal operation and during single phase-to-ground fault respectively. Main effect of single phase-to-ground fault can be observed at figure 9-b. Especially current of $\mathrm{C}$-phase has a peak value of approximately 700 Amperes during fault occurs on it. Also this level is appropriate by actual value that is given in figure 5 .

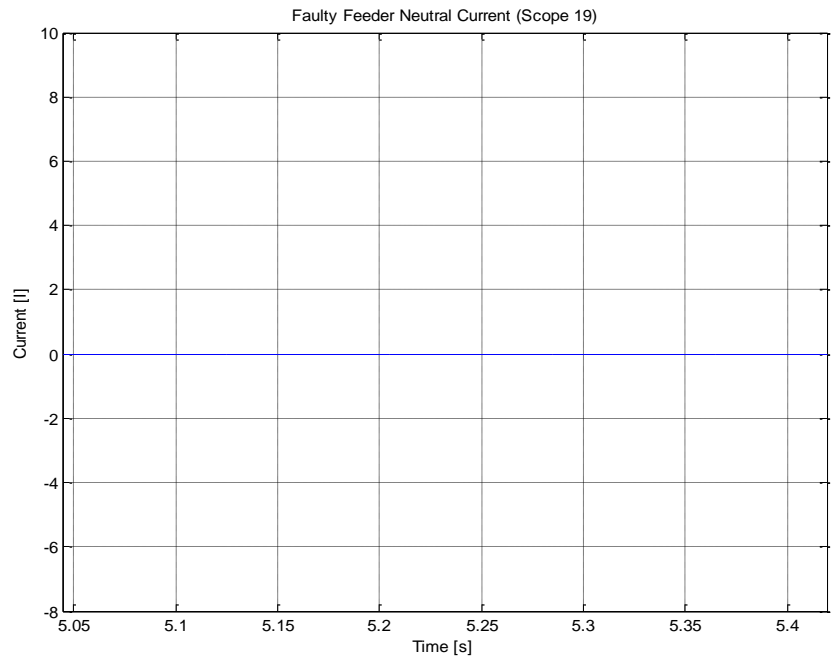

Figure 10-a. Neutral current graph of faulty feeder at normal operation

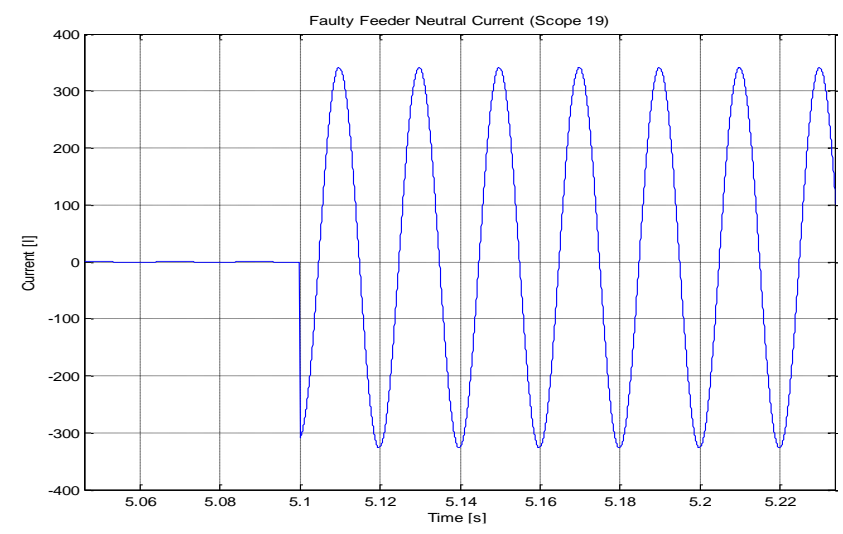

Figure 10-b. Neutral current graph of faulty feeder during fault conditions

Figures 10-a and 10-b show the neutral current of faulty feeder at normal operation and when the fault occurs respectively. As it is used for the validation of the simulation design, normal operation current is zero where the fault time neutral current is 341 Amperes.

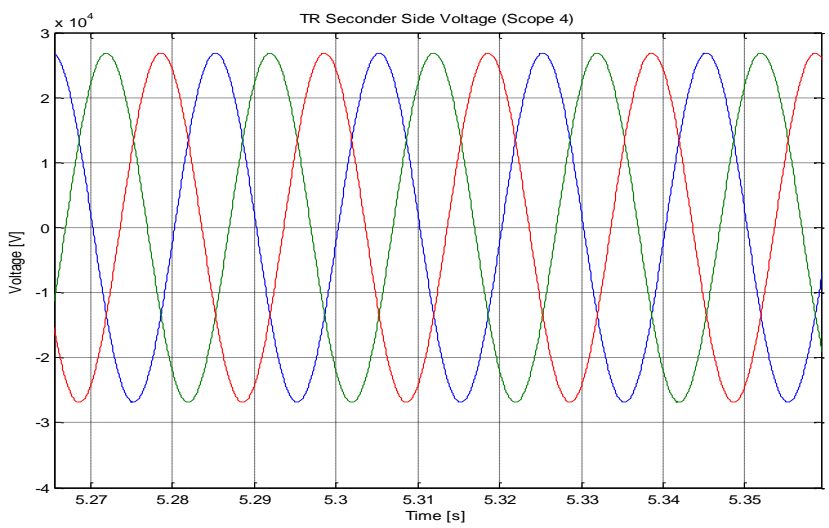

Figure 11-a. Voltage graph $33.6 \mathrm{kV}$ side of transformer at normal operation

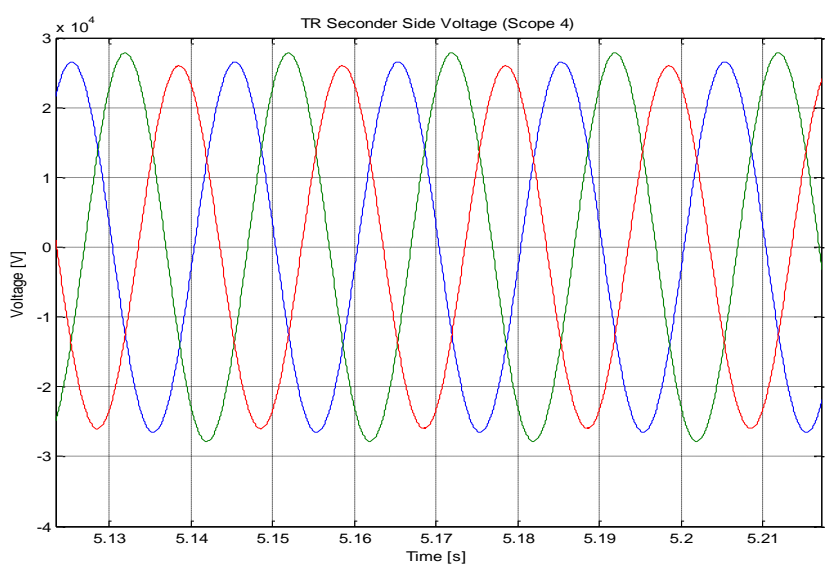

Figure 11-b. Voltage graph $33.6 \mathrm{kV}$ side of transformer in faulty conditions

For determining effects on voltage levels of system, figures 11a and 11-b are obtained from secondary side ( $33.6 \mathrm{kV}$ side) of transformer. As the $\mathrm{C}$-phase is represented by red line, it can be seen from waveforms that single phase-to-ground fault affect secondary side voltage at tolerable levels. 


\section{Conclusion}

Fault analysis is one of the vital study in power systems because of its ability to supply system data for power engineers under abnormal conditions. But it is not always possible to determine the effects of faults at every point of power system. Developments in computer systems and also simulation software, allow the engineers to design and simulate a power system under a simulation platform to analyze it both for normal operation and fault conditions.

In this paper, single phase-to-ground fault condition of an actual power system (154 kV Van Substation) is modelled by MATLAB / Simulink to determine effects of fault currents at various points and also the behavior of the system under faulty conditions. First, actual graphs of the system which are taken from relays and the graphs of designed Simulink model are compared. Comparison results prove the designed Simulink model is appropriate and can represent the actual system. Once the simulation system is accepted as it gives true results, graphs that are taken from various points of system and how the single phase-to-ground fault which occurs at C-phase affect the system are investigated.

Results of this study can guide engineers and power system designers for important points which have to pay attention on, especially during design stage of power systems.

\section{References}

Butler-Purry,K.L., Wang,H. 2003 Computer Models of Internal Short Circuit and Incipient Faults in Transformers. IEEE PES Transmission and Distribution Conference and Exposition, pp.1027.

Han, F., Yu, X., Al-Dabbagh, M., Wang, Y. 2007 Locating Phase-toGround Short-Circuit Faults on Radial Distribution Lines. IEEE Transactions on Industrial Electronics, 54 (3): 1581-1590.

Huang, S.J., Wan, H.H. 2010 A Method to Enhance Ground-Fault Computation. IEEE Transactions on Power Systems, 25 (2): 11901191.

Küçük S., 2005. Elektrik Tesislerinde Arızalar, (In Turkish), TÜPRAŞ Türkiye Petrol Rafinerileri, İzmit, Turkey

Mützel, T., Berger, F., Anheuser, M 2007 Numerical Analysis of LowVoltage Circuit-Breakers under Short-Circuit Conditions. The 53rd IEEE Holm Conference on Electrical Contacts, pp. 37-42.

Parise, G. , Massimiano, M. ,Halpin, M. 1995 Short Circuit Analysis On a Simple Power System Network: The "Characteristic" Currents Method. Proceedings of the Twenty-Seventh Southeastern Symposium on System Theory, pp. 30-34.

Schlabbach J., 2005. Short-circuit Currents, Institution of Engineering and Technology, United Kingdom.

Serrican, C. 2007 Petkim Petrokimya Aliağa Tesisi'nin Elektrik Sisteminin Yük Akışı ve Kısa Devre Hesapları. MsC. Thesis (In Turkish), Istanbul Technical University, Istanbul, TURKEY. 